\title{
Malignant Pancreatic Gastrinoma
}

National Cancer Institute

\section{Source}

National Cancer Institute. Malignant Pancreatic Gastrinoma. NCI Thesaurus. Code C67458.

A gastrin-producing neuroendocrine tumor arising from the pancreas. It is characterized by inappropriate secretion of gastrin and associated with Zollinger Ellison syndrome. It displays vascular invasion and metastasizes to other anatomic sites. 